\title{
IGUALDAD, REPRESENTACIÓN Y VIOLENCIA DE GÉNERO: EL FEMINISMO EN LAS DRAMATURGAS DEL SIGLO XXI
}

\author{
EQUALITY, REPRESENTATION AND GENDER VIOLENCE: \\ FEMINISM IN THE $21^{\text {st }}$ CENTURY SPANISH THEATRE
}

\section{María del Pilar JÓDAR PEINADO}

mpjodar@gmail.com

Universidad de Salamanca

Resumen: En estas primeras décadas del siglo xxI, es evidente el interés por la visibilización de las dramaturgas españolas vivas, que se lleva a cabo en el contexto de las teorías feministas contemporáneas. Partiendo de este contexto y teniendo en cuenta que las dramaturgas que escriben en la España actual proceden de diversas generaciones, analizo quince textos teatrales, publicados o estrenados en este siglo, en la medida en que respondan a alguna de las reivindicaciones del feminismo.

Palabras clave: Teatro español. Feminismo. Dramaturgas. Dramaturgia emergente.

Abstract: In last decades of $\mathrm{XXI}^{\mathrm{ST}}$ century, there was an increasingly interest about women playwrights, which takes place within the context of contemporary Feminist theories. Taking this into account and considering that actual women playwrights come from different generations, I have analyzed sixteen plays, published or performed in the $\mathrm{XXI}^{\mathrm{sT}}$ century, according to some kind of Feminist reivindication. 
Key Words: Spanish Theatre. Feminism. Women Playwrights. Emerging Playwrights.

\section{EL ESTUDIO DE LAS DRAMATURGAS ESPAÑOLAS EN EL SIGLO XXI}

La dramaturgia femenina española suscita gran interés en estas primeras décadas del siglo, a juzgar por la cantidad y calidad de estudios dedicados a este asunto. En primer lugar, citaría las antologías de Raquel García Pascual (ed.), Dramaturgas españolas en la escena actual (2011) y Francisco Gutiérrez Carbajo (ed.), Dramaturgas del siglo XXI (2014); así como el proyecto europeo DRAMATURGAE $E^{1}$, que pretende estudiar el teatro actual escrito por mujeres y en español, promovido por el profesor Romera Castillo (director del Centro de Investigación de Semiótica Literaria, Teatral y Nuevas Tecnologías, UNED), con participación de la UNED, la Universidad de Toulouse y la de Giessen, y de donde surgen, respectivamente: Dramaturgias femeninas en la segunda mitad del siglo Xx: espacio y tiempo (Romera Castillo, ed., 2005), El personaje teatral: la mujer en las dramaturgias masculinas en los inicios del siglo XXI (Romera Castillo, ed., 2009), Transgression et folie dans les dramaturgies féminines hispaniques contemporaines (Garnier / Roswita, eds., 2007) y Dramaturgias femeninas en el teatro español contemporáneo: entre pasado y presente (Floeck et alii, eds., 2008).

El Centro de Investigación de Semiótica Literaria, Teatral y Nuevas Tecnologías tiene como una de sus líneas centrales de investigación al teatro español ${ }^{2}$, una de cuyas vertientes está dedicada a las dramaturgas, como puede verse en: "Estado de la cuestión: siglos xx y XxI. Las dramaturgas y el SELITEN@T” (Romera Castillo, 2011). Del mismo modo, dentro de su línea de investigación sobre la reconstrucción de la vida escénica en España en los siglos XIX, XX y XXI, existe una parte dedicada a las dramaturgas españolas, como muestra el estudio de Miguel Ángel Jiménez Aguilar (2014), en el número 21 de la revista Signa, quien cita, además, en

1.Les Anacroniques-Roswita. Españ@ 31: http://blogs.univ-tlse2.fr/lla-espana31/les-roswita/

2. Como puede verse en http://www2.uned.es/centro-investigacion-SELITEN@T/ estudios_sobre_ teatro.html [26/04/2017]. 
esta parcela, a Valeria Maria Rita Lo Porto y Anita Viola (Jiménez Aguilar, 2014: 496).

Las dramaturgas también son objeto de estudio por parte de la sección del citado Centro de Investigación dedicada a la escritura autobiográfica ${ }^{3}$, como se puede ver en trabajos como: "De la historia a la memoria: recursos mitológicos y autobiográficos en algunas dramaturgas del exilio" (Romera Castillo, 2008).

Por otro lado, cabe destacar el número 21 (2012) de Signa, cuyo "Estado de la cuestión 1" versa "Sobre lo grotesco en autoras teatrales de los siglos xx y xxI"; así como el 28 de Acotaciones (2012), con una sección dedicada a las dramaturgas emergentes: "Siete textos breves de siete dramaturgas jóvenes. Imágenes de una sociedad violenta" (Pérez Rasilla, 2012).

\section{LAS MUJERES EN EL TEATRO DEL SIGLO XXI: PERSONAJES Y DRAMATURGAS}

Aunque las cuestiones de género no son específicas de las dramaturgas ni del siglo XXI, sí es ahora cuando adquieren mayor visibilidad, como afirma Virtudes Serrano (2016: 49).

Es evidente la destacable presencia de personajes femeninos para determinados autores, entre los que podría citar, por nombrar algún ejemplo, a José Sanchis Sinisterra, Paco Bezerra, o Alfredo Sanzol. Del primero podríamos nombrar, en esta centuria, La máquina de abrazar (2009), con dos mujeres unidas en la amistad y la solidaridad, y de finales del siglo xx, Perdida en los Apalaches (1990), Bienvenidas (1993), Valeria y los pájaros (1995) o El lector por horas (1999). Del mismo modo, Paco Bezerra coloca a cuatro mujeres como protagonistas de El señor Ye ama los dragones (2013), además de la importancia que adquieren sus personajes femeninos en obras como Grooming (2009), Dentro de la tierra (2008) o El pequeño poni (2016). Alfredo Sanzol, por su parte, destaca con Delicadas (2011) y con la gran protagonista de La respiración (2017).

No obstante, podríamos citar tres ámbitos en los cuales parece predominar la presencia de personajes femeninos en este siglo: la historia,

3. Centro de Investigación de Semiótica Literaria, Teatral y Nuevas Tecnologías (José Romera Castillo, dir.): http://www2.uned.es/centro-investigacion-SELITEN@T/escritura_autobio.html[26/02/2017]. 
el mundo del teatro (donde se puede incluir, el mundo del arte, en general) y la violencia.

Sobre figuras femeninas históricas hablan J.A. Hormigón y M. Fox en El personaje teatral: la mujer en las dramaturgias masculinas en los inicios del siglo XXI (Romera Castillo, ed., 2009); concretamente, M. Fox se centra en Clara Campoamor y Victoria Kent, objeto de revisión por parte de Jerónimo López Mozo en Las raíces cortadas (2011). Del mismo modo, podríamos citar La excelente señora (2002), de Antonio Ballesteros, donde Juana la Beltraneja se reivindica como reina; Nefertiti y PII (2016), de Beatriz Cabur o Zahra, favorita de Al-Ándalus (2005), de Antonia Bueno, de las que trataré a continuación.

La relevancia de los personajes femeninos es tal que incluso contamos con un grupo de obras protagonizadas por actrices y dramaturgas, quienes manifiestan problemas específicos de la profesión teatral ligados a su sexo ${ }^{4}$. Así, por ejemplo, en cuanto a actrices, contamos con La puta enamorada (2000), de Chema Cardeña; Bel la Bella (2013), de Antonia Bueno; o Proyecto Bruckner (2010), de Laura Rubio Galletero, ejemplos a los que se pueden sumar, si miramos a los últimos años del siglo xx, E.R. (1995), de Josep Maria Benet i Jornet; o Interpretación (1999), de María José Ragué-Arias. Por otra parte, en lo que se refiere a dramaturgas, cabría mencionar Juicio a una dramaturga (2004) y Caídos del cielo (2009), ambas de Paloma Pedrero; Nefertiti y PIII (2016), de Beatriz Cabur; o Y yo sin enterarme (2015), de Antonia Bueno.

Dentro del tema de la violencia, específicamente, la que se ejerce contra las mujeres y las niñas, Virtudes Serrano (2016: 52) señala textos de autores hacia finales del siglo xx (siguiendo la estela de feministas como Lidia Falcón con No moleste, calle y pague, señora, de 1984), como Comisaría espacial para mujeres (1994), de Alberto Miralles y Solo para Paquita (1991), de Ernesto Caballero, quien además escribe, ya en este siglo, Sentido del deber (2005), estudiada por Javier Huerta Calvo (2009), como un caso de violencia de género.

En realidad, la atención a las agresiones machistas forma parte de una tendencia en el teatro de este siglo (procedente de la anterior centuria)

4. Estos textos pueden revisarse en las páginas correspondientes de Metateatro español en el umbral del siglo XXI: el mundo del teatro y el teatro del mundo (2016), M.P. Jódar Peinado y de "El metateatro como testimonio del quehacer dramatúrgico y escénico en siete textos teatrales del siglo xxI" (2016), M. P. Jódar Peinado. 
que tiene que ver con la violencia en sus diferentes manifestaciones: abusos, torturas o xenofobia, ejemplo de los cuales son Hamelin (2005), de Juan Mayorga; Juegos prohibidos (2002), de Alberto Miralles; o Terror y miseria en el primer franquismo (2002), de José Sanchis Sinisterra, por citar algunos.

Las dramaturgas emergentes, como explica Pérez Rasilla (2012) y veremos a continuación, participan de esta tendencia, con la diferencia de que la atención a la violencia de género se realiza con una perspectiva feminista, que actualiza este tema y lo sitúa en el contexto actual de las luchas de este movimiento.

\section{TEATRO FEMINISTA}

Como ya señaló César Oliva (2002: 321), los últimos años del siglo Xx significaron el afianzamiento de la dramaturgia femenina en España:

El deseo de afirmar un papel hasta el momento extraño a su campo de acción, hizo que aparecieran numerosos textos creados por mujeres. [...]. De manera que los últimos años del siglo $x x$ han servido para normalizar el desembarco de autoras en el fenómeno de la escritura teatral. (Oliva, 2006: 55)

De sus palabras podemos extraer que, desde el inicio de este “"renacer' de la dramaturgia femenina en España" (Serrano, 2006: 101), las dramaturgas ejercieron su profesión conscientes de sus dificultades y con el propósito de superar la secular discriminación de las mujeres en este campo. En este momento, es de justicia nombrar la importante labor de Carmen Resino, Paloma Pedrero o Lidia Falcón, entre otras, creando la Asociación de Dramaturgas (1986), dirigida por la primera de ellas, y la publicación de la antología Dramaturgas españolas de hoy, una introducción (1988), de Patricia W. O'Connor. En cuanto a la Asociación de Dramaturgas, la propia Paloma Pedrero comentaba en su Facebook, recientemente, el carácter cohesivo y fundacional de esta agrupación, que pretendía visibilizar a las creadoras destacándolas frente a sus compañeros dramaturgos: 
La primera Asociación de Autores de Teatro fue de Autoras de Teatro 5 (mediados de los años 80). [...]. Carmen Resino [...] fue la primera Presidenta. Un día nos dijimos, tenemos que abrir la Asociación a los autores varones. Poco después nacía la AAT en la que nos mezclamos, y en la que todavía no ha habido ninguna autora Presidenta. Cosas del patriarcado dificiles de erradicar (14 de julio de 2015).

Esto es, podríamos decir que este arranque de la dramaturgia femenina a partir de 1990 se vincula con un feminismo consciente, por ejemplo, en el caso de Paloma Pedrero, según establecen Jonh P. Gabriele (1994) y Virtudes Serrano (2013), que se convierte en un rasgo definitorio de su sobra.

Esta conciencia feminista se puede observar en dramaturgas del siglo XXI, como Diana I. Luque o Lola Blasco. Para Luque, este autorreconocimineto promovería la incorporación de las dramaturgas a la escena teatral española: "La toma de conciencia sobre la tradicional discriminación de las mujeres en el ámbito dramatúrgico está acelerando y facilitando su incorporación al panorama teatral español" (Luque, 2014: 44). Por su parte, Lola Blasco, recientemente galardonada en su labor dramatúrgica con el Premio Nacional de Literatura Dramática 2016, reconoce una lucha explícita de las dramaturgas contra la sociedad patriarcal: "Las dramaturgas están buscando la forma de definirse, combatiendo las imágenes que les vienen siendo impuestas por una sociedad y una cultura patriarcales" (Gutiérrez Carbajo, 2014: 141).

Es evidente, por tanto, la vinculación del teatro de nuestras dramaturgas con un feminismo que les aportará un discurso en el encauzar sus preocupaciones y ejercer una función que trasciende lo puramente teatral, para tratar de implicar a la sociedad en las cuestiones que afectan a las mujeres, tales como la violencia que se ejerce sobre las mujeres y las niñas, además de otros asuntos como la lucha por la igualdad de oportunidades y la reivindicación de referentes femeninos en ámbitos como el arte. Se hace necesaria, por tanto, una "perspectiva feminista",

5. Mientras reviso estas páginas, se anuncia en la propia página de la AAT, un cambio de nombre por el que, sin afectar a las siglas, pasa a llamarse Autoras y Autores de Teatro, a instancias de las propias dramaturgas y para promover su visibilización (https://www.facebook.com/permalink.php?story fbid $=1402770$ $516411711 \& i d=132205430134899[19 / 04 / 2017])$. 
según la autora Vanesa Sotelo (Gutiérrez Carbajo, 2014: 398) que encauce las preocupaciones de estas dramaturgas sobre la situación de las mujeres en el mundo. Esta relación del feminismo con el teatro la establece ya Gutiérrez Carbajo en la introducción a su antología (ed., 2014).

El feminismo del que se hacen eco nuestras autoras puede definirse como "una ideología filosófica, un movimiento social y un programa político", según Lidia Falcón (2014: 212). No obstante, además de las reivindicaciones que caracterizan el feminismo actual, nuestras dramaturgas recogen problemas mundiales derivados de la crisis global: "El feminismo contiene en su ideología y en su práctica, la denuncia de todas las opresiones y la defensa de todos los oprimidos" (Falcón, 2014: 213). Se pretende, así, que las mujeres también realicemos aportaciones para la conformación de un mundo más justo. Este feminismo universalista es asimismo señalado por Amelia Valcárcel: "El feminismo es, por descontado y por su raíz ilustrada, un universalismo" (Valcárcel, 2006: 13). Esta filósofa, además, conecta con la idea de Celia Amorós (2005: 29) acerca de la infrarrepresentación femenina, con su teoría de la cruel dinámica de las excepciones, según la cual, una mujer que acceda a la elite pensante, no redimirá a sus congéneres, sino que será tratada como una excepción:

El que una mujer goce de un talento excepcional la convierte en una excepción sobre todo a su sexo; sin embargo, precisamente por ser considerada una excepción, no obliga a variar el escaso aprecio que se tenga del talento del sexo femenino en su conjunto (Valcárcel, 2009: 31).

Para ilustrar estas dificultades con las que se encuentran las mujeres en el mundo globalizado, he pretendido rastrear elementos feministas en las obras escritas por mujeres, para lo cual, he escogido quince obras, estrenadas o publicadas en el siglo xxI, pertenecientes a dramaturgas reconocidas nacional e internacionalmente con diversos galardones y que trabajan en la creación teatral comprometidas con el contexto inmediato y con la investigación artística. Por supuesto, no aparecen todas las dramaturgas que deberían, ya que este trabajo pretende tan solo establecer unas líneas temáticas a partir de las cuales se pueda profundizar en el feminismo implícito y explícito de nuestro teatro contemporáneo. 


\subsection{Violencia de género}

La violencia machista se ha convertido en una de las preocupaciones fundamentales del feminismo, por lo que se trata de un tema que las dramaturgas españolas van a analizar con una clara voluntad de denuncia y concienciación social. En los textos analizados encontramos tanto violencia de género en la pareja como abusos a niñas o mutilación genital. El tratamiento de este tema comienza por la abierta exposición de la violencia, para terminar con un análisis de las causas, apuntando al machismo social.

La violencia de género es el tipo de violencia que se ejerce contra las mujeres por el simple hecho de serlo, y así lo expresan las personajes de Selección natural (2007), de Pilar Campos Gallego: "Mujeres que conciben mujeres. Ni siquiera mujeres. Enfermas. Que sufren por ser mujeres y mueren por ser mujeres" (Campos Gallego, 2007: 175).

En la dramaturgia actual encontramos desde la más cruda representación de la violencia hasta la indagación en sus orígenes, que están, sin duda, en el machismo imperante en la sociedad, y que tiene formas sutiles de enmascararse como el acoso callejero contra el que se rebelan las actrices-personaje de Kamouraska (2010), de Vanesa Sotelo: "Marta. - Cuando un tío me diga que tiene miedo porque tres mujeres se suben la falda delante de él y empiezan a masturbarse, entonces empezaremos a hablar de igualdad (Sotelo, 2014: 415).

En la obra que más directamente se representa esta violencia es en ¡Arriba la Paqui! (2007), de Carmen Resino, cuya protagonista sufre el maltrato por parte de su marido, Dani, quien irrumpe en la escena dando muestras de la humillación y el abuso al que la tiene sometida:

(Dani da una sonora bofetada a Paqui que la saca de su semi-ensoñación.)

¡En vez de tanta peluquería y tanta mierda, lo que tenías que hacer es estar en casa, planchándome las camisas! [...]. (Volviéndola a agarrar y zarandeándola.) [...] Pues que despierte y se entere de la puta que tiene de madre (Resino, 2007: 19). 
Otra obra en la que también se realiza un violento relato de agresiones es en Las variaciones del golpe (2012), de Vanessa Montfort. Daniel, hijo de una víctima, ha decidido denunciar a su padre, pero el abogado de este trata de evitarlo mediante la intimidación y la humillación. Daniel explica así alguno de estos episodios violentos que padeció en su infancia: "Él nos pegaba. [...]. Mi madre me contó que una vez me sentó con tal fuerza en el banco de la cocina que perdí el conocimiento" (Montfort, 2012: 144)

La violencia contra las niñas está representada en Fictionality Shows (2012), de Diana I. Luque, en forma de los abusos que un padre comete contra su hija. La fingida y socialmente aceptada felicidad familiar encubre humillaciones y abusos cotidianos que Luque quiere poner en evidencia a través de la ficción dentro de la ficción que constituye un macabro programa de televisión dentro de la propia obra de teatro.

En esta obra, un padre de familia, en connivencia con una cadena televisiva, organiza el secuestro de su propia hija, Luz, para que su mujer, Alba, les encuentre en menos de una hora. El objetivo es que, a cambio de ofrecer este espectáculo, la familia gane un millón de euros. A medida que se va desarrollando esta macabra persecución, se van poniendo en evidencia algunas contradicciones de la tan ilusionante vida ideal, una de las cuales sería el abuso que parece ejercer el padre de Luz sobre su propia hija, y que se deja traslucir en este diálogo tan característico de la obra por su singularidad formal:

Ella.- Su marido nunca secuestraría a su hija, ni por un millón ni por cien millones [...] le dejaría jugar a la consola y le prepararía el baño y le pondría el pijama para que Alba no vea las heridas ni los cardenales en sus muslos [...] para que no vea la sonrisa esbozada en el rostro de su marido mientras pasa la esponja por el cuerpo diminuto y magullado de su hija.

Él._para que no piense que él la lastima o abusa de ella (Luque, 2012: 134).

También sobre las niñas, fundamentalmente, se ejerce la mutilación genital, otro tipo de violencia de género, tema de El impronunciable jardín de Chiswick (2014), de Beth Escudé i Gallès. Precisamente, su protagonista, Fadouma, alude a la preocupación del feminismo por la ablación, práctica 
a la que es difícil oponerse, ya que se encuentra enraizada en su cultura: "Las feministas ya por entonces se compadecían de nuestras niñas abladas y de las que estaban por ablar. Pero eran conscientes de la complejidad del asunto" (Escudé i Gallès, 2014: 246).

A la denuncia de esta violencia le sucede la investigación de sus causas y la denuncia del desamparo institucional al que se ven abocadas las víctimas, como vamos a ver en los textos de las dramaturgas consultadas.

La falta de empatía de las instituciones encargadas de velar por la vida de las mujeres se ve claramente en Invisible (2014), de Aizpea Goenaga, donde Mila, la protagonista de esta pieza, además de haber sufrido violencia machista, ha de padecer los interminables interrogatorios que ponen en duda su carácter de víctima. A partir del momento en que la protagonista acude al hospital para ser tratada de las agresiones, se ve obligada a someterse al juicio de todas las personas que le rodean: desde su madre, su amiga y su cuñada, hasta la enfermera, la agente o la abogada, mientras que el agresor permanece invisible durante toda la obra.

Por un lado, la Enfermera comienza su intervención con: "Menuda avería te ha hecho..." (Goenaga, 2014: 271). Este personaje repite varias veces que tiene que marcharse o que acaba su turno, de manera que deja desamparada a la víctima o a expensas de una nueva Enfermera que volverá a hacerle las mismas preguntas: "Me voy. Enseguida vendrá mi compañera" (Goenaga, 2014: 282). La amiga también repite esta frase que rompe la empatía con la víctima, después de echarle en cara no haber dejado antes a su marido: "Es que no entiendo cómo le aguantas. Me tengo que marchar" (Goenaga, 2013: 276). Por otro lado, la Agente también demuestra falta de tacto cuando parece que va a hacerse cargo de la denuncia por agresión machista: "La Agente.- Cuénteme su versión de lo sucedido. / Mila.¿Versión?" (Goenaga, 2013: 273).

Algunas de estas trabas administrativas son señaladas por el sórdido abogado de Las variaciones del golpe (2012), de Vanessa Montfort. Daniel, el hijo de la víctima, no desiste en su empeño de denunciar a su padre, de modo que el abogado de este trata de intimidarlo haciéndole creer que no tiene posibilidades en un juicio y que será ninguneado por el sistema judicial si no tiene conocimientos o amparo profesional:

Daniel.- Pero me he estado asesorando y ahora tengo ahorrado. He leído muchos libros. Y teníamos algunos 
derechos.

Abogado.- Mira, chaval. ¿Quieres que te hable de la administración pública, de la mayoría simple y de la jurisprudencia o de un decreto ley? [...]. Aunque todo lo que cuentas fuera verdad, te van a sacar la pasta, y no te va a servir de nada (Montfort, 2012: 147).

Desgraciadamente, las prácticas intimidatorias y manipuladoras del abogado surten efecto. El sistema acosa tanto a las víctimas que estas renuncian a denunciar su caso por miedo a quedar desamparadas y sufrir una nueva y definitiva agresión: "Si se entera de que le he puesto una denuncia vendrá a por mí" (Goenaga, 2013: 276), afirma Mila, la protagonista de Invisible.

Una de las causas de la reticencia a denunciar es que las víctimas pueden ser culpadas de la agresión que han sufrido; es decir, en ocasiones les hacen responsables de su situación. La víctima, por tanto, es colocada en una encrucijada que la incapacita para actuar, situación simbolizada en la indecisión final de Mila, en Invisible (2014), acerca de si contestar o no al teléfono de Javier, su marido y agresor, que suena esperando insistentemente.

La culpabilización de las víctimas la ejerce el siniestro abogado de Las variaciones del golpe quien, en primer lugar, justifica las agresiones, para luego normalizarlas y, finalmente, traspasar la responsabilidad a la víctima. Así, el Abogado responde a Daniel con el reconocido comentario de: "Algo haríais tú y tu madre" (Montfort, 2012: 141), para después convertir la agresión en algo positivo: "Y porque tu padre te pegaba has aprendido a pegar. ¿A que esto no lo habías pensado, crío de mierda?" (Montfort, 2012: 144), e incluso convertir al agresor en un salvador: "Abogado.- Mira, tu padre se fue de casa. [...]. Se fue de casa para no haceros daño" (Montfort, 2012: 142). Pero su manipulación llega a su punto más alto cuando termina acusando a Daniel de victimista: "Daniel.—Dejó a tres niños pequeños dependiendo de un sueldo. / Abogado.— Y dale con el victimismo" (Montfort, 2012: 146), para después acusar a su propia madre: "Ni tu padre era tan malo, ni tú tan bueno, ni tu madre tan buena [...]. Sí, sí... ha destrozado una fa-mi-lia" (Montfort, 2012: 141). De este modo, ha conseguido absolver completamente a su cliente para convertir a la víctima en causante de la agresión. 
En Invisible (2014), de Aizpea Goenaga, la familia de Mila también trata de minimizar el problema espetándole las manidas consignas que responsabilizan a la víctima de su situación, evitando, así, tener que ocuparse de este asunto. Por un lado, la madre de Mila le aconseja no abandonar a su marido; por otro, su amiga la culpabiliza por no haberse divorciado antes: "Ay, si se veía venir. Os teníais que haber separado hace mucho" (Goenaga, 2014: 275); y su cuñada disculpa a su hermano, el agresor, convirtiéndolo en la víctima: "A ver... que te has metido ahí tú solita. Y que mi hermano no está viviendo un infierno para que tú vivas como una reina. Vamos..." (Goenaga, 2014: 278).

La culpabilización de la víctima se inserta dentro del discurso patriarcal que normaliza la violencia de género, representante del cual es el abogado de Las variaciones del golpe (2012), de Vanesa Montfort. A lo largo de la conversación con el hijo de su cliente que ocupa toda la obra, el Abogado mostrará todos los tópicos que se asocian con la violencia machista. Para empezar, Adriana califica así al padre de Daniel: "Su padre, eso es verdad, era muy machista..." (Montfort, 2012: 139); pero es inmediatamente callada por el Abogado que la agasaja y manipula con juicios sobre su apariencia física: "Mírala. Ya viene. Está un poco fondona pero en cuanto se cuide un poco..." (Montfort, 2012: 142); o "Tú tienes unas buenas tetas y para qué las vas a disimular" (Montfort, 2012: 142), hasta que llega a espetarle: “¿Tú, Adriana, me considerarías a mí capaz de hacerte el amor? ¿A que sí?” (Montfort, 2012: 148).

Ante la incapacidad del sistema para asumir y erradicar este tipo de violencia, las víctimas han de idear maneras de sobrevivir. La Paqui de Carmen Resino (2007) se inventa una vida ficticia: cree que es una famosa del mundo televisivo que está siendo entrevistada, hasta que su marido real, Dani, irrumpe en escena de forma agresiva poniendo en evidencia la naturaleza de la ensoñación de Paqui. Esta capacidad evasionista de la víctima, lejos de ser considerada un obstáculo, es vista por Jennifer Zachman (2007: 12) como una oportunidad de luchar contra la situación de violencia que está sufriendo: "The only suggestion of hope is, potentially, that if women like Paqui have the strength to create their own fictional escape, then perhaps they can eventually garner the courage to reshape their reality".

En cierto modo, Fadouma de El impronunciable jardin de Chiswick (2014), de Beth Escudé, también se inventa otra vida. Miente para simular 
que realiza ablaciones y poder, así, tener una nueva vida. Fadouma vive en Inglaterra y, como método de subsistencia, se dedica a practicar ablaciones, pero estas no son tales sino unos pequeños cortes para simular la extirpación del clítoris. La protagonista se ve empujada a este trabajo como único medio de subsistencia, "único trabajo de prestigio que podía ejercer una mujer africana" (Escudé i Gallès, 2014: 246) dada la marginalidad a la que se vio abocada una vez establecida en Europa.

Así que, cuando la televisión británica irrumpe en la clínica de Fadouma para denunciar las prácticas ablatorias, lo que descubren es un fraude que se realiza en aras de salvaguardar la vida: "Y, por todo ello, así me declaro, Señorías: culpable" (Escudé i Gallès, 2014: 248).

Llama la atención que tanto Fadouma como Paqui hablen directamente al público, ficcionalizado en el tribunal que le acusa de regentar una clínica ilegal y en los espectadores del programa televisivo, respectivamente. Fadouma y Paqui son personajes metaficcionales en la medida en que se dirigen al público rompiendo la cuarta pared, traspasando las fronteras de la ficción para, así, implicar a la audiencia y hacerla partícipe y cómplice de su situación.

\subsection{La desmitificación de la feminidad}

Las imposiciones de los cánones de belleza patriarcal, así como de determinadas normas de conducta asociadas con el género femenino, son consideradas violencia simbólica. La filósofa Celia Amorós (2005) y la dramaturga Angélica Liddell (2005) explican cómo los cuerpos femeninos son el espacio de dominio patriarcal sobre el que se ejerce la violencia. Es por esto que, Angélica Liddell y Pilar Campos Gallego llaman la atención sobre el cuerpo femenino, a través de la violencia ejercida por parte de las propias mujeres, como forma de transgresión, produciéndose, de este modo, una resemantización de su corporalidad, de su espacio.

Contra la imposición de los cánones de belleza claman las tres actricespersonaje de Kamouraska (2014), obra abiertamente reivindicativa de la dramaturga feminista Vanesa Sotelo. Cada una de las ocho "embestidas" en las que se divide la obra desmantela alguno de los valores o conceptos claves de la sociedad patriarcal. Por ejemplo, en la Quinta Embestida, las personajes claman contra la exigencia de la belleza, visibilizada en forma de juicios constantes sobre el aspecto de las mujeres: "Marta.— Que si 
tienes que estar depilada, que si las uñas, que si la ropa... ¿Tú sabes la cantidad de tiempo que lleva eso? Y no me vengas con que son cinco minutitos porque lleva mogollón de tiempo y ese tiempo sería fantástico si se invirtiese en leer a Foucault" (Sotelo, 2014: 415).

Del mismo modo, la Miranda shakespeariana de Lola Blasco (2014), en Ni mar ni tierra firme (Tres monólogos sobre La tempestad) — quien ha vuelto a la isla de su destierro cargando con el cadáver de su padre, para enterrarlo allí y cumplir la última voluntad de este- es emisora de algunas de las peticiones feministas más importantes. Por ejemplo, se queja a su padre muerto de la imposición violenta del mito de la belleza: "Las princesas poseen su belleza, ese es su valor durante un tiempo. Después liftings, liftings hasta la saciedad" (Blasco, 2014: 155).

Frente a la obligatoriedad de la belleza, las dramaturgas prefieren hablar de la menstruación, que parece ser un tema tabú, aportándole una dimensión mítica y trascendente, como hace el personaje de Ribeta en $\mathrm{Mi}$ agravio mudó mi ser (2016), de Laura Rubio Galletero: "Mis ovarios son dos granadas. Cada ciclo lunar es un parto fallido, una explosión en el eje de la vida donde mana la sangre para limpiar mis pecados" ${ }^{6}$. Otro intento de luchar contra este tema tabú lo constituye Sancha, reina de Hispania (2005a), de Antonia Bueno, donde la primera menstruación de la reina es objeto de un ritual celta: "Siti._ Esta sangre, sangre de vida es. Mientras tu sangre fluya, fluirá tu vida. (Sombría). Esta no es sangre derramada... no es sangre de muerte" (Bueno, 2005a: 12).

La sexualidad femenina tampoco parece ser un tema usual y de eso se aprovecha Fadouma, de El impronunciable jardin de Chiswick (2014), para realizar sus falsas ablaciones. Como forma de liberarse de las posibles represalias, Fadouma decide simular este tipo de mutilaciones ya que en su clínica "podía NO hacer lo que NO quisiera" (Escudé i Gallès, 2014: 247), aprovechándose del desconocimiento y falta de interés por la sexualidad femenina:

Ningún hombre iba a hurgar entre el sexo de su hija, esposa o amante. [...]. No constatarían si realmente habían sido extirpados los labios superiores. Aún menos utilizarían los castos dedos de su mano derecha para separar y comprobar

6. Esta obra fue estrenada por la Compañía de Creación Escénica, en el Festival Clásicos Luchana, Teatros Luchana, Madrid, 2016. Está inédita, de manera que no incluyo números de página porque el texto en el que me he basado no está publicado, sino que es una aportación personal de la autora. 
el recorte en labios inferiores o asegurarse que el tajo del clitoris era suficientemente limpio y profesional. Tampoco sus lenguas sospecharían, porque no las utilizan. El sexo femenino es feo para los míos y no tienen trato con él. Esa era mi baza (Escudé i Gallès, 2014: 247).

El éxito silencioso de Fadouma radica, aparte de en la salvación de vidas, en la plena vida sexual que podrán mantener sus clientas, quienes no vuelven a pedir su dinero porque no se les ha practicado la mutilación pactada: "Algunas se convierten en multiorgásmicas clandestinas y su única mutilación es no poder compartirlo alegremente con sus amigas. [...]. He defraudado a mis clientas que no se retuercen de dolor durante el coito" (Escudé i Gallès, 2014: 248).

Esta visibilización de la sexualidad femenina se enmarca en la defensa de la libertad de las mujeres frente a las imposiciones del patriarcado. Esta lucha tiene su mejor representante en la Leonor de Mi agravio mudó mi ser (2016), de Laura Rubio Galletero, que se atreve a romper con los dictados del patriarcado emprendiendo el camino de la libertad, tan peligroso como inexplorado, pero que ha de construirse a medida que se transite por él.

En esta obra, Laura Rubio realiza una dramaturgia sobre textos propios y de otras autoras - como, por ejemplo, Ana Caro Mallén, de quien procede el verso que da título a la obra-, para articular discursos feministas que pone en boca sus personajes. Estas proclamas versarían sobre la libertad de decidir de las mujeres, contra la manipulación consentida de los donjuanes que han protagonizado la literatura y sobre la desmitificación del amor romántico.

Leonor y Estela son dos víctimas de los engaños de don Juan; sin embargo, mientras que Leonor pretende vengarse de su burlador asesinándolo, Estela se deja llevar por sus ensoñaciones románticas y pretende convertirse en su esposa y en madre de sus hijos. Es por esto por lo que la enamorada convence, finalmente, a la burlada para que esta no lleve a cabo su crimen. La acción entre estas dos mujeres y la criada de Leonor, Ribeta, se desarrolla trufada de interesantes pensamientos que dejan al descubierto un trasfondo feminista.

Leonor, en su alegato final, juega con la subversión del significado de obsceno que, normalmente, se refiere a lo que se separa de la norma, de lo establecido, pero que ella relaciona con la violencia de sujetarse, 
precisamente, a las imposiciones de la sociedad:

Lo obsceno para mí es la palabra amor. [...]. Amor, obsceno es que el amor sea nuestra única vía de supervivencia. Hablar del amor, pensar en el amor, compartir amor con mis semejantes. Amor. ¿Existe otra prioridad? [...]. El amor no me ha salvado. El amor casi me mata. Se me metió dentro y me echó.

La Zahra magrebí de Zahra, favorita de Al-Ándalus (2005b), de Antonia Bueno, también emprende este desconocido, pero necesario, camino de la libertad: "Allí donde voy no seré una 'ladrona de empleo'. Trabajaré y ganaré mi dinero. No tendré que depender de ningún hombre. Podré ser tan sólo una mujer. Buscaré con uñas y dientes mi libertad" (Bueno, 2005b: 35).

La coacción a las libertades de las mujeres comienza por la cantidad de mensajes contradictorios que recibimos en nuestra juventud, sobre los que reflexiona Ribeta, criada de Leonor, en Mi agravio mudó mi ser (2016): "Sé una cabra loca, aprovecha jovencita aunque, ojo, ve sentando la cabeza no vayas a quedarte sola, no vayas a vestir santos y se te pase el arroz". Estas recomendaciones pueden ser consideradas una forma de violencia social en cuanto a que infantilizan a las mujeres y las culpabilizan en el caso de no cumplirlas. Culpabilización que alcanza, incluso, al derecho a decidir sobre el propio cuerpo, contra lo que se queja una de las personajes de Kamouraska (2014), en clara alusión a los vaivenes legislativos a que se somete el derecho al aborto: "Marta._ ¿Y por qué tienen que meter sus rosarios en nuestros ovarios?" (Sotelo, 2014: 422).

Y es que, como dice María, en esta misma obra, Kamouraska (2014): "Parir no quiere decir amar. [...]. Parir no significa querer dar vida" (Sotelo, 2014: 405), lo que nos lleva al tema de la desmitificación de la maternidad, tema principal de Selección natural (2007), de Pilar Campos Gallego. En esta obra se subvierte el papel de la madre y su función primordial como cuidadora y protectora, según explica Isabelle Reck (2007). En la primera parte de esta obra, "Marcas para un itinerario", tres mujeres de la misma familia hablan de la enfermedad de ser mujer, esposa y madre, de la abnegación y entrega a los cuidados de las personas mayores y del marido, de lo que la Abuela y la Madre advierten a su hija: "Madre.— Ana, cariño, 
dile que siempre le tendrás preparada una comida deliciosa para cuando él regrese del trabajo [...] pero cariño también le dirás que nunca... nunca te quedarás embarazada" (Campos Gallego, 2007: 171).

La subversión del papel de la familia como un entorno protector continúa en la segunda parte de esta obra, "Control Room”, donde Lynndie, madre, enseña a Jessica, su hija, técnicas de tortura y dominación que luego esta practicará con su marido, Ramón, en lo que parece un ajuste de cuentas por no compartir las responsabilidades en la pareja: “¿No sabes que hay que coger el teléfono cuando te llaman? / ¿Eh? ¿No sabes que la basura hay que bajarla todos los días?" (Campos Gallego, 2007: 192-193), grita Jessica mientras le sujeta el cuello con una cuerda. La subversión del papel de madre y esposa abnegada se realiza, por tanto, mediante el ejercicio de la violencia que hace a las mujeres reapropiarse de su espacio, de su cuerpo.

Isabelle Reck (2007) vincula a Pilar Campos Gallego con Angélica Liddell por realizar un tipo de teatro cercano al tema de la perversidad y en el que también se representa ese rechazo a la maternidad. La denominada narradora épica (Reck, 2007: 174) de Lesiones incompatibles con la vida (2011), de Angélica Liddell, considera la oposición a la maternidad como una posición ideológica frente al sistema capitalista, su forma de protestar, como repite varias veces a lo largo del texto: "No quiero tener hijos. / [...] / Mi cuerpo es mi protesta" (Liddell, 2011: 161); "No quiero aportar nada al mundo, salvo mi profundo horror por el mundo" (Liddell, 2011: 162).

La autora arremete contra la falsa idea de que nuestro aporte obligatorio a la humanidad en forma de descendencia siempre será positivo y esperanzador: "Los adultos saltan por encima de mi vientre liso agitando a sus hijos como banderas [...] como si fueran insignias de un futuro mejor" (Liddell, 2011: 161).

El rechazo consciente ala maternidad comopostura vital inconformista contra el mundo también sirve para desmitificar la institucionalización de la familia: "No quiero formar una familia. Nunca me fiaría de una institución que es fomentada, ensalzada, vitoreada, incluso premiada por el poder. [...]. No puedo fiarme de algo que es impuesto desde el poder. No puedo fiarme de algo que es impuesto desde la religión" (Liddell, 2011: 64).

Precisamente, el alegato más importante de la Miranda de Lola Blasco (2014) es contra la imposición de la maternidad: 
Si pudiera borrar en mí la posibilidad de parir un hijo... Ya estoy, de nuevo, restregándome en mis conflictos interiores. Tú no tienes conflictos, los conflictos los tienen las mujeres: madre o individuo, madre o individuo. Madres mártires vencidas pero invencibles, ansiosas por sacrificarse, madres de héroes, soldadas de Dios... No, ya no pende sobre mi el hacha, quiero decir el hecho, que se da con la maternidad. En realidad, creo que no me ha deseado nunca (Blasco, 2014: 152).

\subsection{Los roles de género en el ámbito familiar}

Una vez establecido el núcleo familiar, los roles de género siguen perpetuándose. Aunque esto no le ocurre a Paula, la madre feminista de En la otra habitación (2006), de Paloma Pedrero, a quien su hija Amanda le reprocha que haya antepuesto su trabajo a su papel de madre: "Amanda.Tú tenías que luchar [...] por la igualdad de sexos [...] por triunfar profesionalmente... [...]. Pero entonces, ¿por qué fuiste madre?" (Pedrero, 2006: 175). Es por esto por lo que, en el tiempo que dura la acción teatral, Amanda ha ideado un plan para frustrar la cita que va a tener su madre con otro hombre que no es su padre y darle, así, una lección. La lucha feminista de Paula es erigida en su defensa ante los reproches de su hija:

Paula.- Yo no tengo la culpa de vivir en una sociedad mal hecha, injusta, canalla con las mujeres. Porque ni te imaginas lo que he tenido que pelear para que me respetasen, para tener mi propio nombre [...]. ;Y ahora, ahora llegas tú, la niñita mimada, la niñita lista, y me lo escupe a la cara! (Pedrero, 2006: 179).

Pero el feminismo de Paula es objeto de ataques y ridiculización por parte de Amanda, a quien le parecen extravagancias:

Paula.- [...] Los hombres se van a hundir con el mundo encima. Con todo su poder debajo del brazo. Con su dinero. Repantingados en el sofá viendo el fútbol. Con su incapacidad para expresar lo que sienten. Con su fuerza 
bruta. Con su egoísmo. Los hombres se van a hundir solos. Amanda.- [...] Tu feminismo ha llegado a altas cotas poéticas (Pedrero, 2006: 175).

La madre de Amanda no se ha dedicado exclusivamente a cuidarla, trabajo contra el que clama la Miranda de Lola Blasco (2014), cuyo monólogo es una revisión desmitificadora de algunos de los tópicos que se asocian al género femenino: "Y ¡claro!, lo normal es lavar al muerto, asearlo y vestirlo para la ocasión. [...]. Limpiar mierda siempre ha sido, por costumbre, un trabajo femenino" (Blasco, 2014: 150).

$\mathrm{Y}$ es que Paula quiere advertir a Amanda acerca de la sociedad machista en la que su hija tendrá que vivir: "Paula.- Y es chungo, es chungo para los hombres, Ami, aceptar que las tías, además de inteligentes, podríamos vivir sin ellos" (Pedrero, 2006: 186).

Del mismo modo que en la obra de Paloma Pedrero, Carmen Resino también nos habla del conflicto generacional en $A$ vueltas con los clásicos (2007), en este caso, representado por una familia que mantiene los clásicos roles de género que, además, se empeña en perpetuar. Adela y Julia son las hijas del Abuelo, un importante estudioso de la Antigüedad, que juzga a estas mujeres en función de su sujeción o no a las imposiciones tradicionales. Este seguimiento de las normas patriarcales lleva a la familia entera a ser cómplice del delito de pederastia que comete Teo, el padre y marido de Julia, contra su propia hija, Helena.

Julia y Adela encarnan dos estilos tradicionales de vida a los que han estado abocadas las mujeres: la esposa y madre abnegada y la soltera despreciada que ha tenido que cuidar del padre, puesto que carece de otras cargas familiares. Julia, le echa en cara a su hermana su elección personal: "Julia.- - No creo que exista una mujer que no quiera tener hijos" (Resino, 2007: 63) y trata de ridiculizarla llamándola feminista, característica que, a juicio de Julia, quedaría invalidada porque está enamorada de su cuñado: “¿Sí, tú sí le perdonarías pese a todas tus ideas tan feministas!” (Resino, 2007: 48). Además de las burlas de Julia, Adela tiene que aguantar los reproches de su propio padre por no haber querido casarse: "Represento para ti un sexo odiado" (Resino, 2007: 45).

Por otra parte, la renuncia y abnegación de Julia es mucho más grave, dado que por salvaguardar el estatus que le proporcionaba su marido, fue capaz de ignorar el abuso al que este sometía a su hija. Adela le echa en 
cara su silencio y Julia responde que lo hizo por el honor: "Tenía que resguardar mi reputación y la de todos. [...]. A eso nos enseñaron, Adela: a guardar las formas, a establecer distancias, a decir sonriendo que todo va bien. [...]. A eso nos enseñaron, Adela: a callar" (Resino, 2007: 49). Julia, para desentenderse de su crimen, culpabiliza a su propia hija del incesto: “¡Tenías que haber visto cómo se insinuaba, cómo coqueteaba con él!" (Resino, 2007: 49).

Finalmente, Teo y Helena, que representan la relación incestuosa entre padre e hija, también reproducen los roles típicos del hombre condescendiente, el maestro que guía a la mujer inexperta, de hecho, así la califica: "Teo.- Yo te liberé de ser una hembrita equivocada y estúpida" (Resino, 2007: 56).

\subsection{La recuperación de las voces femeninas}

La reivindicación de las mujeres silenciadas por la historia es otra de las luchas feministas, puesto que la visión histórica parcelada ha ocultado numerosos hechos importantes y ha privado de referentes femeninos a generaciones de mujeres.

En Juicio a una dramaturga (2004), la ya citada Paloma Pedrero aporta la visión de las mujeres sobre el mundo del teatro en este monólogo claramente feminista. Después de morir, una dramaturga se despierta en el juicio que decidirá si va al cielo o no, para lo cual ha de convencer al jurado - el público - de que su vida no merece el descanso infinito en el paraíso, sino que prefiere la inmortalidad del arte. La Mujer no merece el cielo, ya que su conducta no ha sido la esperable en una mujer: se ha dedicado a buscar incansablemente su sitio en el mundo teatral. Se trata de un comportamiento que puede resultar peligroso, como bien advierte $\mathrm{La}$ Mujer en la Sombra de Nefertiti y PIII (2016) ${ }^{7}$, de Beatriz Cabur, al personaje de la Autora: "Ten cuidado con tanta ambición, no es un atributo que se les permita tener a las mujeres" (Cabur, 2016: 42). De hecho, a la Autora no se le permite y es secuestrada por Amenohtep como representante del Club de Hombres, asociación que conspira para promover la invisibilización de las mujeres y, concretamente, de las de esta obra.

La Autora trata de montar El horizonte del sol, una obra que rescate

7. Estrenada en 2015 en la Sala Berlanga (Madrid). 
la figura de Nefertiti, utilizando, para ello, a su investigadora en el siglo xx. Sin embargo, la Autora se encuentra con la oposición de su personaje, la Mujer en la Sombra, con quien mantiene una discusión pirandelliana cuando esta se niega a salir a la luz por miedo a las represalias de los hombres del Club:

Los hombres de tu vida. Los hombres de la mía. [...]; los que ni se sabe que están y controlan todo; [...]; los que están mejor valorados aunque sean peores; los que llegan más alto que tú y son unos ineptos que no te llegan ni a la suela de los zapatos [...]. Los hombres en general. Los que deciden nuestro rumbo y destino (Cabur, 2016: 32).

Este miedo desemboca en el propio rechazo de la Mujer en la Sombra a ser la protagonista de la obra, poniendo de relevancia el hecho de cómo se articula la Historia oficial, ignorando siempre la parte de la que son protagonistas las mujeres.

Asimismo, la Mujer de Juicio a una dramaturga (2004) también llama la atención sobre la ausencia de mujeres en el ámbito público: "De pequeña ya vivía asombrada. No entendía por qué el mundo era como era, ni por qué no salían mujeres en los telediarios, ni por qué mi hermano, que era un ñoño, tenía una paga dominical mayor que la mía" (Pedrero, 2004: 320). La Miranda de Lola Blasco también se quejaba de la escasa representación femenina en la historia de la literatura o de la imagen tradicional de la mujer en el arte: "No, no hay historias de princesas así en tu biblioteca. Siempre hemos existido pero nunca hemos hablado. Las historias de príncipes que se rebelan a sus padres, que destronan a sus padres son muchas, pero princesas... princesas deseantes..." (Blasco, 2014: 155). A causa de esta superpoblación de princesas en el arte, Miranda afirma haber pensado quemar la biblioteca de su padre, en un claro acto subversivo que simbolizaría su toma de conciencia como mujer que habita un entorno patriarcal.

El viaje de Miranda es un ajuste de cuentas con su progenitor muerto, una revisión de su papel como hija que tiene voluntad de erigirse en denuncia contra la representación de la mujer en la Literatura. Esta Miranda señala la dificultad de las mujeres para acceder a la esfera pública, para que se las tome en serio: "Los hombres ignoran hasta qué punto está 
todo escrupulosamente organizado para que ellos triunfen sin arriesgar demasiado, creen que su superioridad se debe a su gran fuerza" (Blasco, 2014: 151).

Esta misma dificultad, las trabas absurdas que se imponen al desarrollo profesional de las mujeres, es asimismo denunciada por la Mujer de Juicio a una dramaturga (2004) quien, como trasunto de la propia Pedrero, hace un recorrido por su obra desvelándonos las circunstancias adversas en cuanto a publicación y difusión de sus piezas. Su primer éxito fue La llamada de Lauren, obra que recibió un accésit a pesar de que según le dijeron - era la favorita del jurado; estas reticencias a otorgarle el primer premio se deben, según su punto de vista, a su condición de mujer en el mundo del teatro: “'Me ha gustado más tu obra, pero...' Es que los peros están en todas partes [...]. Pero en el teatro, en el teatro escrito por una mujer joven, auténtica, bronca y española cosecha del 57, el pero ha sido de campeonato" (Pedrero, 2004: 322).

En definitiva, durante toda su vida, la Mujer ha tratado de que tomaran en serio su trabajo como escritora, así que este empeño no la hace merecedora del cielo. En realidad, ella no quiere pasar la eternidad en el paraíso, porque va a tener que seguir cumpliendo las reglas preestablecidas para ella y para el resto de las mujeres; por el contrario, prefiere ser reconocida y recordada por sus obras de teatro.

Como la protagonista de Juicio a una dramaturga (2004), las dos Zahras de la pieza de Antonia Bueno (2005b) se rebelan contra lo que la sociedad tiene destinado para ellas. Estas se sienten encerradas y así manifiestan sus gritos de libertad: "Zahra magrebí._-iNo puedo salir de este encierro!" (Bueno, 2005b: 13); Zahra andalusí.- (Agitándose como una fiera enjaulada). "iQuiero salir de aquí!” (Bueno, 2005b: 24). Respecto a Zahra andalusí, esta se queja de que no puede salir de su palacio, de su jaula de oro: "Por muy amante que sea Abderramán, yo estoy siempre aquí... encerrada... sometida a su capricho... Paso interminables horas sin hacer nada" (Bueno, 2005b: 31). Del mismo modo que Abderramán tiene a su Zahra enclaustrada en su palacio, el marido de Zahra magrebí, en el siglo XXI, también la mantiene encerrada en contra de su voluntad: “¿Mi casa?... Estoy cansada de dar vueltas como una mula en la noria, alrededor del patio. Necesito romper este círculo... abrir la puerta... Salir..." (Bueno, 2005b: 43).

La protagonista de esta obra, Zahra, — probablemente, la pieza más 
feminista de la Trilogía de Mujeres medievales, según su autora-, es una mujer legendaria a quien Abderramán III dedicó la ciudad de Medina Azahara. La reivindicación de Antonia Bueno, a un tiempo histórica, social y feminista, pretende contraponer esta supuesta figura histórica a la de las nuevas Zahras que habitan nuestro país pero que llegan en patera, aprovechando el aquí y ahora del teatro.

Beatriz Cabur procura, asimismo, reivindicar la figura de Nefertiti, personaje que debiera ocupar un puesto predominante en la corriente oficial de pensamiento: "Responsable y ejecutora de la primera revolución religiosa de la historia y condenada a ser un mero busto bonito en un museo. Reducida a la narrativa masculina. El mayor mérito de la mujer es la belleza. Qué ignominia" (Cabur, 2016: 43). Su historia, la de una mujer gobernadora y legisladora, es demasiado revolucionaria para poder ser contada: "Esa historia no se puede contar ni tres mil años más tarde. [...]. Tuviste más poder ejecutivo del que tuvo ningún hombre en tu época, eso no se puede contar. [...]. Tú gobernaste como mujer. No siguiendo las normas del Club" (Cabur, 2016: 44).

Del mismo modo, se quejan las Zahras de Antonia Bueno (2005b), personajes "que no han tenido acceso a las narrativas canónicas y hegemónicas de la identidad", en palabras de Celia Amorós (2005: 40), que reivindican ser escuchadas y por lo que Zahra andalusí se enfrenta al Narrador: “¡No, narrador! ¡Basta ya! ¡Se acabó! No me gusta el papel que me has asignado" (Bueno, 2005b: 34).

La anécdota final que explica el origen de la historia que acabamos de presenciar vuelve a dar autoridad a la voz femenina:

Narrador. - Un día... hace ya algún tiempo... una pequeña marroqui acompañó a una mujer española a visitar su kashba en ruinas. La pequeña era pastora de cabras y no sabía leer ni escribir [...]. La mujer española le regaló su bolígrafo. La mujer era escritora, había bajado al sur en busca de historias. [...]. La niña se hizo mayor y aprendió a escribir [...]. Y escribió la historia de Zahra. Esta que escuchasteis es su historia (Bueno, 2005b: 74). 


\section{CONCLUSIONES}

Podemos afirmar que el teatro del siglo XxI escrito por mujeres cuenta con una importante presencia de temas y motivos feministas, a la luz de un rápido repaso por algunas de sus producciones. Este tipo de teatro feminista que se consolida a finales de los ochenta y, plenamente, en los noventa, con las aportaciones de Lidia Faldón, Paloma Pedrero, Ana Diosdado, Carmen Resino o Antonia Bueno, por nombrar a algunas, encuentra su continuidad en las dramaturgas emergentes, de entre las que podríamos citar a Lola Blasco, Beatriz Cabur, Diana I. Luque, Laura Rubio Galletero o Vanesa Sotelo.

Este feminismo que se ejerce de manera consciente, como bien afirman estas dramaturgas, es una forma de procurar la normalización de la presencia de mujeres en la escena española y de incorporar la perspectiva femenina a los problemas derivados de la globalización, tomando como referencia un feminismo universalista e integrador. El sustrato feminista que se observa en las obras de nuestras dramaturgas no solo aporta un ámbito de denuncia sino un análisis de las causas de la violencia de género y la desigualdad, que son los temas preponderantes. Por tanto, este feminismo no pretende relegar a las mujeres a la marginalidad por tratar unos temas que afectan exclusivamente a sus congéneres, sino concienciar de los asuntos que afectan a la mitad de la humanidad.

Lo que podríamos llamar teatro feminista o teatro con referencias feministas recoge y actualiza tendencias que están en el teatro de nuestro siglo para actualizarlas en un discurso integrador con voluntad de trascender el ámbito estrictamente escénico e influir en la capacidad crítica del público. Los temas y motivos feministas, por tanto, insertan a nuestras dramaturgas en las preocupaciones generales del teatro contemporáneo, fundamentalmente, a través de dos vías: la violencia (abusos, torturas, xenofobia, asesinatos machistas) y la atención a los personajes femeninos, temas, ambos, por los que se apreciaba un interés, ya en el siglo anterior, también por parte de los dramaturgos. No obstante, este tipo de teatro, además de recoger estas tendencias que están en nuestro teatro, las actualiza articulándolas en un discurso universalista para la reivindicación y la trascendencia extraescénica. Esto es, nuestras dramaturgas recogen el tema de la violencia y lo concretan en la violencia de género aportándole un discurso que permita analizar las causas; por otro lado, se hacen eco 
del interés por los personajes femeninos actualizando las preocupaciones de género hacia cuestiones más específicas como, la desigualdad, la invisibilidad en el ámbito público, el acoso callejero, la imposición de los cánones de belleza o la exigencia de la maternidad o del amor.

Así pues, por un lado, nuestras dramaturgas feministas enlazan con un tipo de teatro, en nuestro siglo, escrito tanto por hombres como por mujeres, con importante presencia de personajes femeninos que representan, en la mayoría de las ocasiones, conflictos de género, visibilizando la violencia o la represión ejercida contra las mujeres y las niñas. Por otra parte, acogen el discurso feminista para contextualizar su lucha que lo es tanto por su propia visibilización en el panorama escénico español como por concienciar sobre los problemas que afectan a mujeres de todo el mundo.

\section{REFERENCIAS BIBLIOGRÁFICAS}

AMORÓS, C. (2005). "Espacios y tiempos en la era de la globalización”. En Dramaturgias femeninas en la segunda mitad del siglo $X X, \mathrm{~J}$. Romera Castillo (ed.), 24-41. Madrid: Visor Libros.

BLASCO, L. (2014). Ni mar ni tierra firme (Tres monólogos sobre La tempestad). En Dramaturgas del siglo XXI, F. Gutiérrez Carbajo (ed.), 143-162. Madrid: Cátedra.

BUENO, A. (2005a). Sancha, reina de Hispania. Alicante: Biblioteca Virtual Miguel de Cervantes. Disponible en línea: $h t t p: / / w w w$. cervantesvirtual.com/nd/ark:/59851/bmcsb4f3 [27/02/2017]. (2005b). Zahra: favorita de Al-Ándalus. Alicante: Biblioteca Virtual Miguel de Cervantes. Disponible en línea: http://www. cervantesvirtual.com/nd/ark:/59851/bmcng509 [27/02/201].

CABUR, B. (2016). Nefertiti y PIII. En 365 Women a Year, AA.VV., Y. García Serrano (prólogo), 15-46. Madrid: Ediciones Antígona.

CAMPOS GALlEGO, P. (2007). Selección natural. Signa. Revista de la Asociación Española de Semiótica 16, 167-193. También en http://revistas.uned.es/index.php/signa/article/view/6156/5889 [10/02/2016].

ESCUDÉ I GALLÈS, B. (2014). El impronunciable jardín de Chiswick. En Dramaturgas del siglo XXI, F. Gutiérrez Carbajo (ed.), 245-248. 
Madrid: Cátedra.

FALCÓN, L. (2014). "Feminismo en tiempos de crisis". En Miradas multidisciplinares para un mundo en igualdad. Ponencias de la I Reunión Científica sobre la Igualdad y Género, M.J. Clavo, y M.A. Goicoechea (coords.), 205-215. Logroño: Universidad de La Rioj. También en https://dialnet.unirioja.es/descarga/libro/435630.pdf [11/04/2017].

FLOECK, W. et al. (eds.). Dramaturgias femeninas en el teatro español contemporáneo: entre pasado y presente. Hildesheim (Alemania): Olms.

FOX, M. (2009). "Victoria Kent y Clara Campoamor en Las raíces cortadas, de Jerónimo López Mozo". En El personaje teatral: la mujer en las dramaturgias masculinas en los inicios del siglo XXI, J. Romera Castillo (ed.), 186-198. Madrid: Visor Libros.

GABRIELE, J. P. (1994). "Metateatro y feminismo en El color de agosto, de Paloma Pedrero". En Actas del XI Congreso de la Asociación Internacional de Hispanistas. La mujer y su representación en las literaturas hispánicas, J. Villegas (coord.), vol. 2, 158-64. California: University. También en http://cvc.cervantes.es/literatura/aih/pdf/11/ aih_11_2_019.pdf [27/02/2017].

GARCÍAPASCUAL, R. (ed.) (2011). Dramaturgas españolas en la escena actual. Madrid: Castalia.

GOENAGA, A. (2014). Invisible. En Dramaturgas del siglo XXI, F. Gutiérrez Carbajo (ed.), 271-284. Madrid: Cátedra.

GUTIÉRREZ CARBAJO, F. (ed.) (2014). Dramaturgas del siglo XXI. Madrid: Cátedra.

HORMIGÓN, J. A. (2009). "Algunas reflexiones sobre el personaje femenino en el teatro del siglo XXI". En El personaje teatral: la mujer en las dramaturgias masculinas en los inicios del siglo XXI, J. Romera Castillo (ed.), 91-101. Madrid: Visor Libros.

HUERTA CALVO, J. (2009). "De doña Mencía de Acuña a Mencía la guardia civil: actualidad y actualización de la tragedia de honor”. En El personaje teatral: la mujer en las dramaturgias masculinas en los inicios del siglo XXI, J. Romera Castillo (ed.), 101-113. Madrid: Visor Libros.

JIMÉNEZ AGUILAR, M.Á. (2014). "Puestas en escena de obras de dramaturgas en la cartelera de Málaga (2000-2003)". Signa. Revista 
de la Asociación Española de Semiótica 23, 495-524. También en http://www.cervantesvirtual.com/nd/ark:/59851/bmc8s6g8 [19/04/2017].

JÓDAR PEINADO, M. ${ }^{a}$ P. (2016). Metateatro español en el umbral del siglo xxi: el mundo del teatro y el teatro del mundo. Madrid: Academia de las Artes Escénicas de España, UNIR (Universidad Internacional de La Rioja). También en http://academiadelasartesescenicas.es/ revista/13/ii-premio-de-investigacion-de-la-academia-metateatroespanol-en-el-umbral-del-siglo-xxi/ [18/04/2017].

(2017). "El metateatro como testimonio del quehacer dramatúrgico y escénico en siete textos teatrales del siglo XXI". En El teatro como documento artístico, histórico y cultural, en los inicios del siglo XXI, J. Romera Castillo (ed.), 230-241. Madrid: Verbum.

LIDDELL, A. (2005). "Un minuto dura tres campos de exterminio". En Dramaturgias femeninas en la segunda mitad del siglo XX, J. Romera Castillo (ed.), 67-75. Madrid: Visor Libros. (2011). Lesiones incompatibles con la vida. Con Tríptico de la aflicción, 161-169. Bilbao: Artezblai.

LUQUE, D. I. (2012). Fictionality Shows. Acotaciones 28, 125-135. También en http://www.resad.es/acotaciones/acotaciones28/luque fictionalityshows.pdf [10/01/2016].

(2014). "Reflexiones sobre la dramaturgia emergente en España: visibilidad y supervivencia en el contexto de las crisis actuales (más una nómina de jóvenes dramaturgos españoles)". En Creadores jóvenes en el ámbito teatral $(20+13=33)$, J. Romera Castillo (ed.), 34-53. Madrid: Verbum.

MONTFORT, V. (2012). Las variaciones del golpe. Acotaciones 28, 137149. También en http://www.resad.es/acotaciones/acotaciones28/ montfort_variacionesgolpe.pdf [10/01/2016].

OLIVA, C. (2002). Teatro español del siglo XX. Madrid: Editorial Síntesis. (2006). "Informe básico sobre la escena española en el siglo XXI". En Los cuadernos de Thalía. Perspectivas del teatro español actual, E. de Miguel Martínez (ed.), 45-66. Gijón: Cátedra Miguel Delibes / Libros del Pexe.

PEDRERO, P. (2004). Juicio a una dramaturga (Yo no quiero ir al cielo). En Teatro breve entre dos siglos, V. Serrano (ed.), 314-330. Madrid: Cátedra. 
(2006). En la otra habitación. En Los cuadernos de Thalía. Perspectivas del teatro español actual, E. de Miguel Martínez (ed.), 147-190. Gijón: Cátedra Miguel Delibes / Libros del Pexe.

PÉREZ RASILLA, E. (2012). "Siete textos breves de siete dramaturgas jóvenes. Imágenes de una sociedad violenta". Acotaciones 8, 7789. También en http://www.resad.es/acotaciones/acotaciones28/ rasilla_teatrobrevejovenesescritoras.pdf [03/03/2016].

RECK, I. (2007). "Teatros síquicos: 'entre fantasma, delirio y muerte', Angélica Liddell y Pilar Campos Gallego". En Transgression et folie dans les dramaturgies féminines hispaniques contemporaines, E. Garnier / Roswita (eds.), 171-184. Carnières-Morlanwelz (Bélgica): Lansman Éditeur.

RESINO, C. (2007). ¡Arriba la Paqui! Estreno 33.2, 14-19. (2011). A vueltas con los clásicos. En Dramaturgas españolas en la escena actual, R. García Pascual (ed.), 42-73. Madrid: Castalia.

ROMERA CASTILlO, J. (ed.). (2005). Dramaturgias femeninas en la segunda mitad del siglo XX. Madrid: Visor Libros.

(2008). "De la historia a la memoria: recursos mitológicos y autobiográficos en algunas dramaturgas del exilio". En Dramaturgias femeninas en el teatro español contemporáneo: entre pasado y presente, W. Floeck et alii (eds.), 123-137. Hildesheim (Alemania): Olms.

(2011). "Las dramaturgas y el SELITEN@T”. En su obra, Pautas para la investigación del teatro español y sus puestas en escena, 381-411. Madrid: UNED. También en http://www2.uned.es/centroinvestigacion-SELITEN@T/pdf/EstudiosTeatro/7Dramaturgas_ siglos XX-XXI.pdf [30/01/2016].

ROSWITA / GARNIER, E. (eds.) (2007). Transgression et folie dans les dramaturgies féminines hispaniques contemporaines. CarnièresMorlanwelz (Bélgica): Lansman Éditeur.

RUBIO GALLETERO, L. (2016). Mi agravio mudó mi ser (inédita).

SERRANO, V. (2006). "Carmen Resino y Paloma Pedrero, dos dramaturgas a un tiempo". En Los cuadernos de Thalía. Perspectivas del teatro español actual, E. de Miguel Martínez (ed.), 97-116. Gijón: Cátedra Miguel Delibes / Libros del Pexe.

(ed.) (2013). “Introducción”. En Pájaros en la cabeza. Teatro a partir del siglo XXI, 9-73. Madrid: Cátedra. 
(2016). “Conflictos de género: hombres y mujeres del teatro español último". Krypton. [Identità][Potere][Rappresentazioni]. Teatro, política 7, 49-56. Roma Tre-Press. También en http://romatrepress. uniroma3.it/ojs/index.php/krypton/article/view/474/471 [18/04/2017].

SOTELO, V. (2014). Kamouraska. En Dramaturgas del siglo XXI, F. Gutiérrez Carbajo (ed.), 403-425. Madrid: Cátedra.

VALCÁRCEL, A. (2006). "Ciudadanía global: sobre identidades, feminismo, globalización y multiculturalidad". Pasajes: Revista de pensamiento contemporáneo 19, 5-14. También en http://roderic. uv.es/handle/10550/46053 [11/04/2017].

(2009). "El feminismo y el saber de las mujeres". Transatlántica de educación. Sexo, género y educación 6, 27-35. México D.F.: Consejería de Educación-Embajada de España. También en https:// sede.educacion.gob.es/publiventa/detalle.action? cod $=15118$ [18/04/2107].

ZACHMAN, J. (2007). “'Arriba la Paqui! de Carmen Resino”. Estreno 33.2, otoño, 11-13.

Recibido el 27 de febrero de 2017.

Aceptado el 3 de abril de 2017. 
